\title{
DEVELOPMENT AND PROTOTYPE TESTING OF AN Agricultural Nozzle Clog Detection Device
}

\author{
C. N. Vong, P. A. Larbi
}

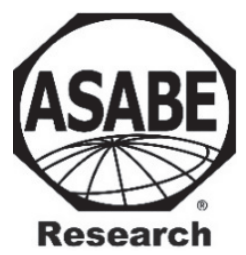

\section{HighLIGHTS}

- Prototypes of an agricultural nozzle clog detection system (for 18 nozzles) have been successfully developed.

- Spray quality characteristics (droplet size, pattern, and coverage) were not significantly affected when testing the device with extended-range nozzles (TeeJet XR8004).

- Most of the spray quality characteristics were significantly affected when testing the device with ultra low-drift nozzles (John Deere PSULDQ2004).

\begin{abstract}
Agricultural nozzles are the main components that perform the spraying of agrochemicals, and their proper functionality is a key element for uniform spray application on crops. Because nozzles have small orifices, they can become clogged when there is debris from the agrochemical in the tank. Nozzle clogging during spray application results in poor pest and weed management and increased cost for re-spraying the affected crop row. Measures used to prevent nozzles from clogging include using screens or strainers to filter out debris before it reaches the nozzle tip, as well as performing regular checks on the nozzles. However, nozzle clogging still occurs during spraying despite the precautions taken. Thus, a device that can detect nozzle clogging during spraying is necessary to enable a quicker response that will ensure uniform application across each row of the crop. A novel, patented device for detecting clogged nozzles that is externally attachable to each nozzle on a sprayer boom was developed in the Precision Application Technology Lab at Arkansas State University. The main objective of this article is to present a general description of this prototype nozzle clog detection device and the nozzle clog detection system. Spray droplet size and pattern tests under controlled conditions and spray coverage tests under field conditions were conducted with and without the device to determine if there were significant differences in droplet size, spray pattern, or spray coverage between using and not using the device. The tests demonstrated that this new technology has potential for detecting clogged nozzles without significantly influencing spray quality for extended-range nozzles but not for ultra low-drift nozzles. To increase the reliability of the performance of this new technology, further improvements in the design need to be considered.
\end{abstract}

Keywords. Clogged nozzle, Detection, Droplet size, Prototype device, Spray coverage, Spray pattern.

A gricultural sprayers are extensively used to apply agrochemicals such as pesticides and fertilizer to crops. Nozzles are the main components that perform the spraying of such agrochemicals, and their proper functionality is a key element for uniform spray application. Because nozzles have small orifices, they can become clogged due to debris from the agrochemical in the sprayer tank. When a nozzle is clogged during spray application and

\footnotetext{
cC)(1) $\odot$ The authors have paid for open access for this article. This work is licensed under a Creative Commons AttributionNonCommercial-NoDerivatives 4.0 International License https://creative commons.org/licenses/by-nc-nd/4.0/

Submitted for review on 27 May 2019 as manuscript number ITSC 13519; approved for publication as a Research Article by the Information Technology, Sensors, \& Control Systems Community of ASABE on 3 November 2020.

The authors are Chin Nee Vong, Graduate Student, College of Agriculture, Food, and Natural Resources, University of Missouri, Columbia, Missouri; Peter Ako Larbi, Assistant CE Specialist, Kearney Agricultural Research and Extension Center and Department of Biological and Agricultural Engineering, University of California, Parlier, California. Corresponding author: Peter Larbi, 9240 South Riverbend Ave., Parlier, CA 93648; phone: 559-646-6577; e-mail: palarbi@ucanr.edu.
}

goes unnoticed by the applicator, a row of the crop may not be sprayed. This will result in poor pest or weed management and increased cost for re-spraying the affected row.

Several publications from different universities (Johnson and Swetnam, 1996; Petroff and Johnson, 2011; Grisso et al., 2013; Hofman and Solseng, 2014) have identified measures used to prevent nozzles from clogging, including the use of screens or strainers to filter out debris before it reaches the nozzle tip, and performing regular checks on the nozzles. Typical strainer types used on agricultural sprayers are tank-filler strainers, line strainers, and nozzle screens (Hofman and Solseng, 2014). The regular checks can include tests to make sure that each nozzle is spraying the same volume of liquid in a smooth pattern, with no heavy streams or blank areas (Grisso et al., 2013). However, nozzle clogging still occurs during spraying despite the precautions taken. Thus, a device that can detect nozzle clogging during spraying is necessary to ensure uniform application across each row of the crop.

Different technologies have been developed to monitor and detect clogged nozzles in agricultural sprayers. Monitoring devices using wire probes placed near the nozzle to detect the 
presence of spray from the nozzle were introduced by Anderson and Hughes (1978) and Vehe and Berg (1980). A flow sensing module, developed by Anderson (1982), was composed of a short PVC plastic or nonmagnetic material housing with a magnetic piston located within its flow passage and a reed switch to indicate continuous flow in the passage. Rogers and Baker (1990) used a horn device to collect sound from spray nozzles to identify clogged or faulty nozzles. A method using the output from a vibration sensor mounted on a nozzle to identify proper operation of the nozzle was suggested by Giles (2007). A monitoring system using a thermal flow sensor positioned within a spray nozzle to detect clogged nozzles was invented by Ellingson et al. (2014). Nevertheless, the need to develop a reliable device that can monitor and detect nozzle clogging during operation, and that is easy to adapt to a wide range of sprayers, is still in demand.

A novel, patented device for detecting clogged nozzles (Larbi and Vong, 2019) that is externally attachable to each nozzle on a sprayer boom was developed in the Precision Application Technology Lab at Arkansas State University. The main objective of this article is to present a general description of this prototype nozzle clog detection device and the nozzle clog detection system. Spray quality tests, including droplet size and spray pattern, under controlled conditions and spray coverage tests under field conditions were conducted with and without using the device to determine if there were significant differences in droplet size, spray pattern, or spray coverage for two types of nozzles between using and not using the device. The results of these tests will facilitate further improvement of the device.

\section{Materials AND Methods Single-Device Prototype}

The prototype of the agricultural nozzle clog detection device consisted of a cylindrical plastic body with electric circuitry built onto it and an attachment on the upper portion of its inner wall. The attachment, which made contact with the host nozzle, was made up of two bolts and nuts as support, a thumbscrew for adjusting the tightness of contact, and foam padding to surround the inner upper part of the device body to prevent damage to the nozzle body. The electric circuitry included a four-pin male connector for connecting to the rest of the system, two prongs that made contact with the spray from the nozzle orifice at the lower portion of the device body, and a light-emitting diode (LED) that lit when there was spray from the nozzle. The prototype device was attached to the nozzle using the attachment described. When the nozzle started spraying and the spray came into contact with the two prongs, the LED lit. When the nozzle was clogged and/or discharging no spray, there was no contact between the spray and the two prongs, the circuit was not complete, and the LED remained off. The device does not depend on humidity but rather works on the principle of prong contact with the developing spray (atomizing liquid) from the nozzle to complete the circuit.

\section{Multiple-Device System Prototype}

To monitor each nozzle along the boom of a sprayer, multiple prototype devices are needed, with each device attached to a nozzle. This prototype multiple-device system can be configured according to the total number of nozzles on the sprayer boom. This study used a precision MudMaster boom sprayer (Bowman Manufacturing, Newport, Ark.) equipped with section control and having nine sections with two nozzles per section. Therefore, the prototype system comprised 18 single devices and a monitoring panel that was located in the cab of the sprayer for the operator to monitor each nozzle. The panel consisted of a switch to turn the system on/off, an indicator light for the on/off status of the system, and LEDs that corresponded to each device.

\section{Droplet Size AND SPRAY PATTERn TeStS UNDER CONTROLLED CONDITIONS}

The tests were conducted in a show barn at the Arkansas State University Farm Complex (or ASU Farm) in Jonesboro, Arkansas. The precision MudMaster boom sprayer described above was used, and two nozzle types were tested: TeeJet extended-range flat tip (XR8004, Spraying Systems Co., Wheaton, Ill.) and John Deere quick-change ultra lowdrift (PSULDQ2004, Deere \& Co., Moline, Ill.). These nozzles represent two of the common nozzle types used by chemical applicators in the Mississippi Delta region. Plain water was sprayed at three operating pressures of 207, 276, and $345 \mathrm{kPa}(30,40$, and $50 \mathrm{psi}$, respectively). Figure 1 is a schematic of the experiment setup. Only sections 1, 2, and 3 (i.e., nozzles N1 to N6) discharged spray, and the boom was set at specific heights from the testing instruments based on the nozzle type used. The instruments were placed directly under nozzle N4. For the droplet size test, the boom height was set to $0.762 \mathrm{~m}$ (30 in.) for both nozzle types to prevent damage to the probe of the droplet counter because the probe was very delicate and highly susceptible to damage. For the spray pattern test, the boom height was set to $0.762 \mathrm{~m} \mathrm{(30}$ in.) for the TeeJet XR8004 nozzles and to $0.508 \mathrm{~m}$ (20 in.) for the John Deere PSULDQ2004 nozzles based on the optimum height suggested by the manufacturers. The two treatments were "with-device" and "without-device".

Before conducting the droplet size and spray pattern tests, the consistency of the flow output was assessed for the 18 nozzles of each type (TeeJet XR8004 and John Deere PSULDQ2004) attached along the boom of the MudMaster sprayer. The sprayer was operated at $138 \mathrm{kPa}(20 \mathrm{psi})$. The flow from each nozzle was collected for 30 s using a Greenleaf calibration container (Greenleaf Technologies, Covington, La.) and a stopwatch. A weighing scale was used to measure the weight of the container before and after collecting the spray. Three measurements were performed for each nozzle, and the average flow output (kg) from the 18 nozzles was computed. The flow output was converted to volume (L) by dividing it by the density of water $\left(1 \mathrm{~kg} \mathrm{~L}^{-1}\right)$. Bar charts of the flow output volume for each nozzle and percentage differences from the average were plotted.

The droplet size test was conducted using a DC-IV portable droplet counter (KLD Labs, Hauppauge, N.Y.), as shown in figure 2. The droplet counter used a hot-wire probe as the sensing component and compiled counts of the sampled droplets to differentiate droplets of various sizes. It can measure water droplet sizes from 1 to $600 \mu \mathrm{m}$. A laptop with the software application for the droplet counter installed was used to 


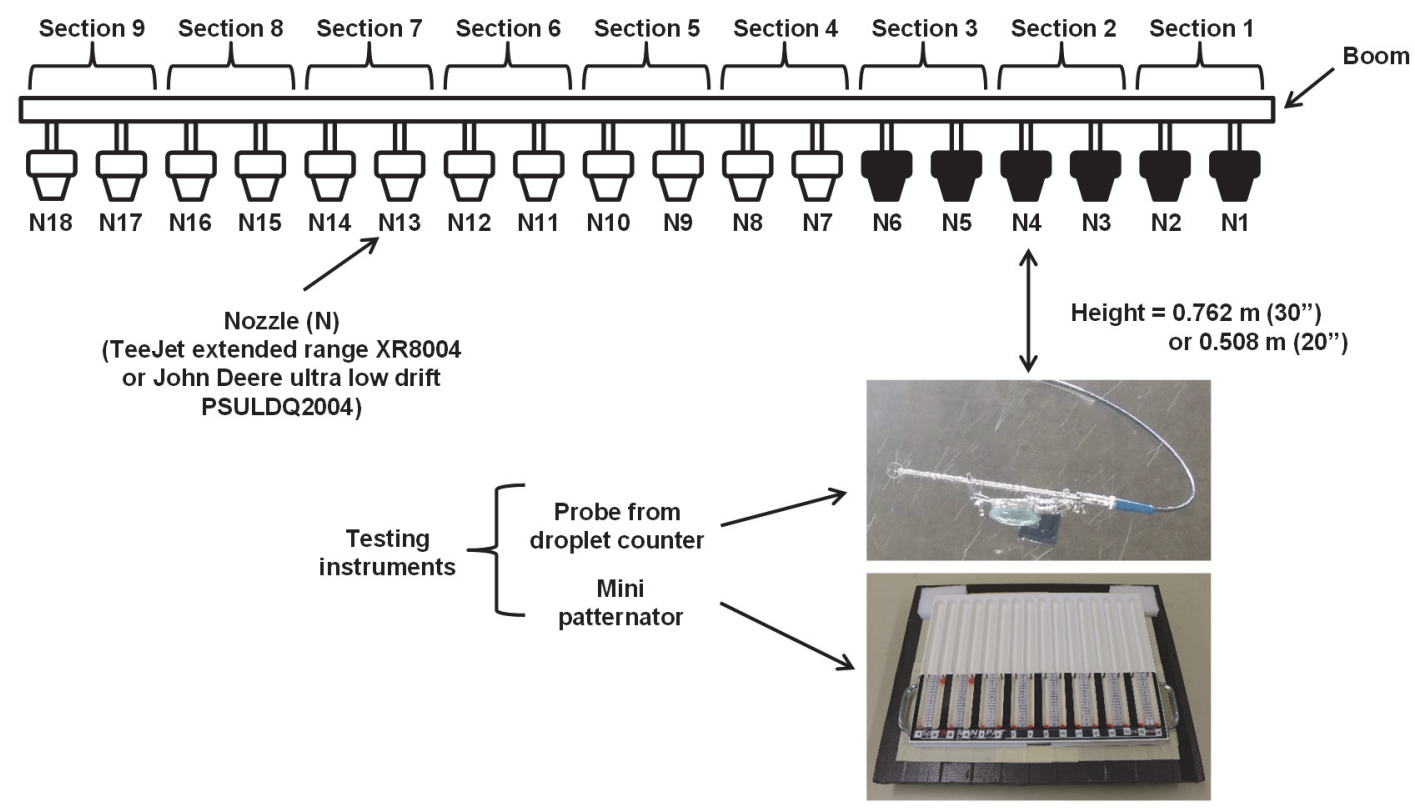

Figure 1. Schematic of experiment setup for droplet size and spray pattern tests. Only the black nozzles (N1 to N6) were used.

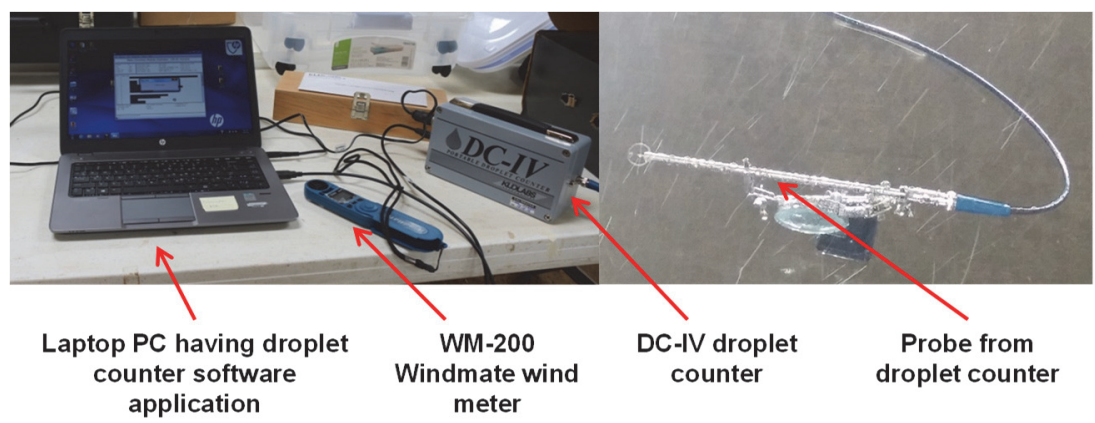

Figure 2. Instrumentation used in droplet size test.

record the measurements. A handheld wind meter (WindMate WM-300, Speedtech Instruments, Sterling, Va.) was used to record the wind velocity, air temperature, and relative humidity for each test. The droplet sampling time was set to $1 \mathrm{~min}$. The collected data were saved as a text file and exported to Microsoft Excel for further analysis.

The average volume of liquid collected for each droplet size was computed among the three replications, and the cumulative percentage volume for each droplet size was also calculated. Scatter plots of cumulative percentage volume for each droplet size for all treatments were plotted for comparison. Furthermore, the average volume median diameter (VMD) was computed from the three replications and presented in bar charts. Two-way analysis of variance (ANOVA) was performed on the average VMD data at 5\% significance level using SAS 9.4 (SAS Institute, Cary, N.C.) to determine whether there were significant interactions between treatments and operating pressures. If there was no significant interaction, the average VMD of each treatment (main effect) for all pressures was computed, and Tukey's honest significant difference (HSD) test was performed at 5\% significance level to obtain a pairwise comparison among the treatments.

A SpotOn mini patternator (Innoquest Inc., Woodstock, Ill.), shown in figure 3 , was used in conducting the spray pattern test. The mini patternator had 16 channels, each having a width of $2.5 \mathrm{~cm}$. Graduated scales $(\mathrm{mL})$ were added to the mini patternator to read the volume in each channel (fig. 3a). A wooden board covered with black duct tape to water-proof it, which had two wheels attached underneath, was used as a platform for placing the patternator (fig. 3a). Masking tape and two L-shaped polyester foam pieces were used as guides for consistently locating the patternator at the same position after removing it to read the measurements. During data collection, when the nozzles started spraying, the patternator was placed on the platform and slid along two aluminum channels (fig. 3a) to position it directly under nozzle N4. The spray liquid was collected within $15 \mathrm{~s}$, and then the patternator was slid in reverse to remove it from the spray. Once removed, the patternator was oriented vertically to read and record the volume of spray liquid collected in each channel (fig. 3b).

The average volume collected in each patternator channel from three replications for each treatment was computed, and line charts were plotted to compare the spray patterns among treatments. The difference in average volume of each patternator channel between the without-device and with-device treatments was computed at different pressures and presented in bar charts. The coefficient of variation (CV) was also computed for each treatment at different pressures and presented in bar charts. For statistical analysis, two-way ANOVA was performed on the $\mathrm{CV}$ data at $5 \%$ significance 


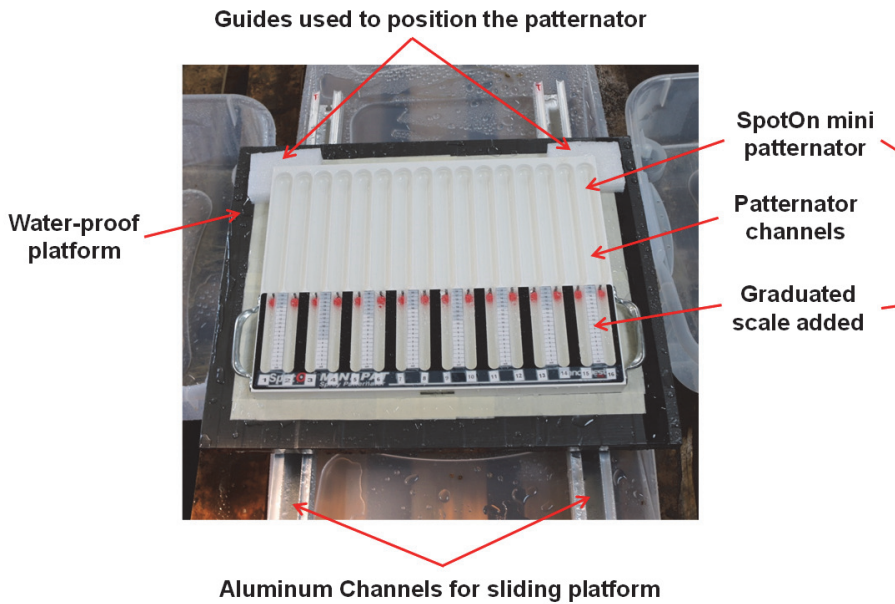

(a)

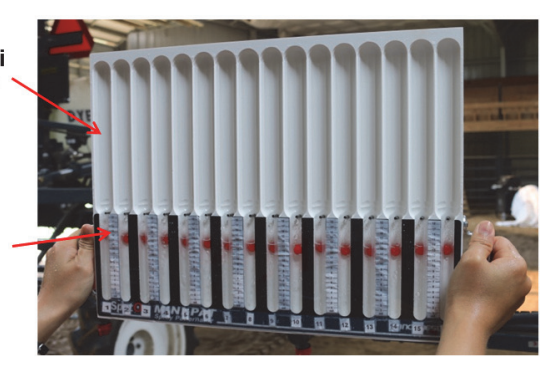

(b)

Figure 3. (a) Instrumentation used in spray pattern test and (b) mini patternator held vertically to read the volume (red ball) in each channel.

level using SAS 9.4 (SAS Institute, Cary, N.C.) to determine whether there were significant interactions between treatments and operating pressures. If there was no significant interaction, the average of each treatment (main effect) for all pressures was computed, and a pairwise comparison among treatments was obtained using Tukey's HSD test at $5 \%$ significance level.

\section{SPRay Coverage Test in Field Conditions}

The spray coverage test was conducted using the precision MudMaster boom sprayer described above. The travel speed of the sprayer was calibrated before performing the spray coverage test. Figure 4 is a schematic of the experiment setup. Three water-sensitive strips, each with dimensions of $50 \mathrm{~cm} \times 2.6 \mathrm{~cm}$, were placed under nozzles $\mathrm{N} 4, \mathrm{~N} 10$, and N15. Three card holders were used to hold the watersensitive strips in position. The test involved combinations of two treatments (without-device and with-device), two application rates of 94 and $187 \mathrm{~L} \mathrm{ha}^{-1}$ (10 and 20 gal per acre, or gpa), two nozzle types (TeeJet XR8004 and John Deere PSULDQ2004), and three replications, for a total of 24 runs. A GreenStar 32630 rate controller (Deere \& Co., Moline, Ill.) mounted on the boom sprayer was used to maintain the application rate as input by the operator. Environmental data consisting of by-the-minute air temperature, relative humidity, and wind speed data from a weather station at the ASU Farm near the test location were retrieved from the website (http://weatherdata.astate.edu). To determine if there were any significant effects of the weather on spray coverage, multiple linear regression analysis was performed with the three environmental parameters as factors to predict the average percentage spray coverage using SigmaPlot 13.2 (Systat Software, San Jose, Cal.).

After each run, each water-sensitive strip was collected and cut in half so that it could be attached onto a letter-sized paper. The paper was then scanned as a JPEG color image using a scanner with a resolution of 150 dpi. The images were rearranged in Microsoft PowerPoint and cropped to a

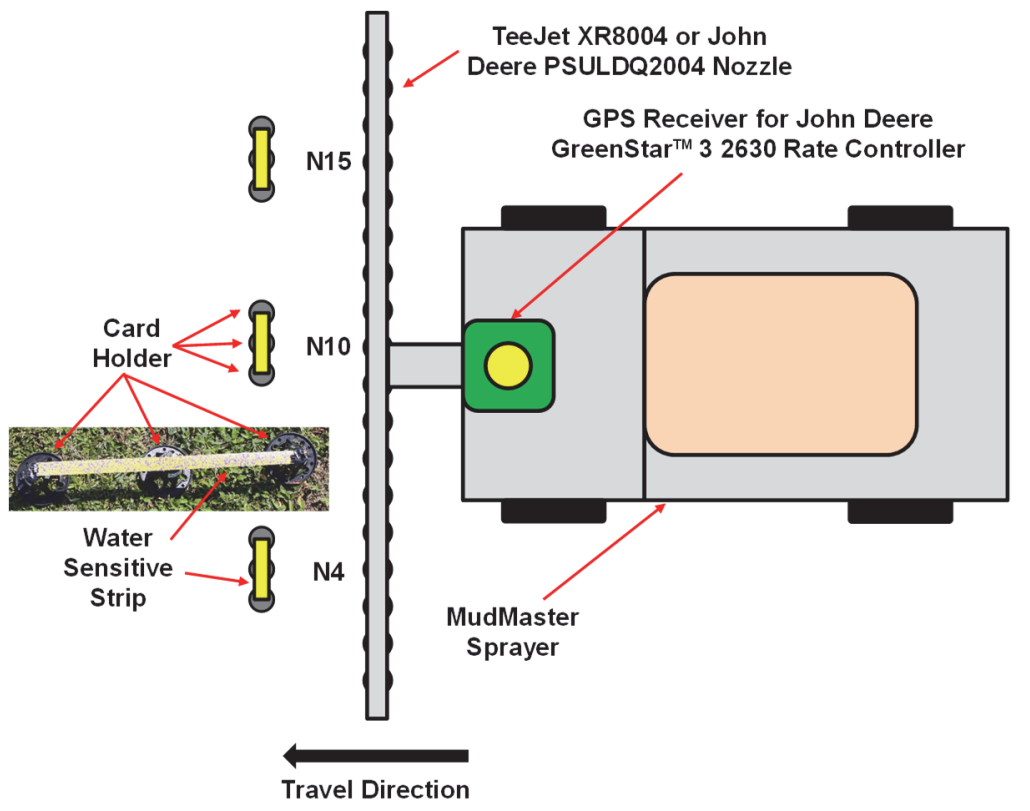

Figure 4. Schematic of experiment setup for spray coverage test. 
consistent size of $8.5 \mathrm{~cm} \times 1.5 \mathrm{~cm}$, representing one of four portions of the water-sensitive strip. The four portions were stitched into a rectangular image of $8.5 \mathrm{~cm} \times 6 \mathrm{~cm}$. The stitched color image was converted to a black-and-white image using the "recolor" tool with the "black and white: 50\%" option selected. The resulting image was then exported as a JPEG image, and its image data were extracted to Microsoft Excel using RGB2X software (Larbi, 2016, 2018) for further analysis. The extracted 8-bit image data had pixel values of 0 to 255 , with 0 indicating pure black color and 255 indicating pure white color. Pixel values less than or equal to a threshold value of 127 were denoted as spotted (covered with spray), and pixel values greater than 127 were denoted as unspotted (uncovered or background). Spray coverage $(\%)$ was computed using equation 1 :

$$
\eta_{\text {coverage }}(\%)=\frac{N_{\text {covered }}}{N_{\text {total }}} \times 100
$$

where

$\eta_{\text {coverage }}=$ percentage spray coverage $(\%)$

$N_{\text {covered }}=$ total number of spotted pixels in image

$N_{\text {total }}=$ total pixels (spotted + unspotted) in image.

The average spray coverage for each treatment at different application rates was then computed and presented in bar charts. Means comparison of average spray coverage between the without-device and with-device treatments was performed using two-way ANOVA followed by Tukey's HSD test, both at 5\% significance level, using SAS 9.4 (SAS Institute, Cary, N.C.).

\section{RESULTS AND DISCUSSION \\ Single-Device Prototype DeVelopment}

Figure 5 shows the prototype of the single-nozzle clog detection device with the components as described in the Materials and Methods section. Initially, the design consisted of one pair of prongs. However, during preliminary testing, the prong design was modified to consist of multiple pairs of prongs, such as three pairs of prongs (fig. 5b), to increase the chances of prongs coming into contact with the spray from the nozzle for different types of nozzle. The single-device prototype was first tested in the Precision
Application Lab using a SpotOn portable spray case (Innoquest, Woodstock, Ill.). The portable spray case had an outlet for attaching a nozzle for testing, and it operated at a maximum pressure of $414 \mathrm{kPa}(60 \mathrm{psi})$. The prototype device worked well when attached to a nozzle that was fitted on the spray case. When there was continuous spray from the nozzle, which maintained contact with the prongs of the device, the LED on the device was continuously lit. When the nozzle stopped spraying (i.e., indicating a clogged nozzle), the LED went off. Multiple prototype devices were successfully tested with similar observations.

The proper functioning of all the prototype units tested indicates that the prototype development was successful. Further testing of the device in different settings will reveal limitations and opportunities for future improvement. Although the prototype was developed using off-the-shelf parts, it serves as a model and contributes important data, which will lead to later development of a commercial product.

\section{Multiple-Device System Prototype}

Figure 6 shows the prototype of the complete nozzle clog detection system, which consisted of multiple devices, based on the number of nozzles on the sprayer, and a monitoring panel located within the cab of the sprayer. The monitoring panel is also shown in figure 6 . The prototype system functioned as expected. The LEDs for the single-device prototypes attached to the nozzles along the sprayer boom and the corresponding LEDs on the monitoring panel were continuously lit when all the nozzles were spraying. When the sprayer operator turned off one of the boom sections to simulate clogged nozzles, the LEDs of the section devices and the corresponding LEDs on the monitoring panel went off. The successful testing of the complete system indicates that the prototype development was successfully accomplished. Further tests of the system will provide critical insights that will lead to a commercial product accessible to producers and chemical applicators.

\section{Droplet Size and SPRAY PATtern Tests UNDER CONTROLLED CONDITIONS}

The spray volumes of the TeeJet XR8004 and John Deere PSULDQ2004 nozzles used in the tests varied within $<4 \%$ of the average volume for all 18 nozzles tested. Hofman and Solseng (2014) stated that a nozzle should be replaced if its

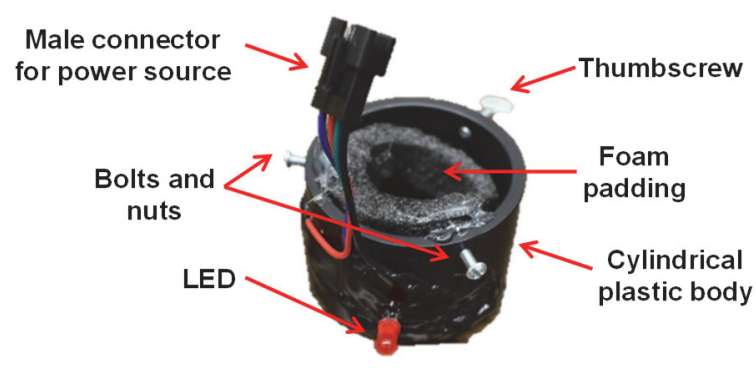

(a)
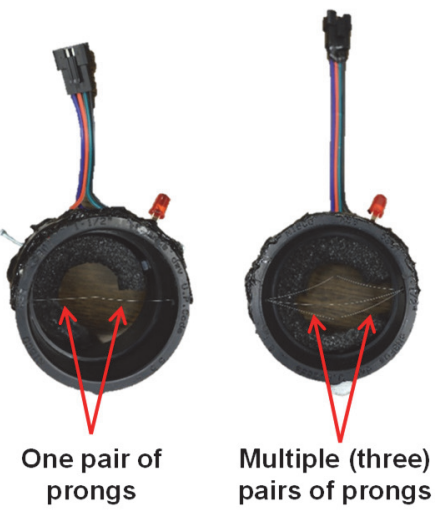

(b)

Figure 5. (a) Prototype of single-nozzle clog detection device and (b) prong designs for prototype device. 


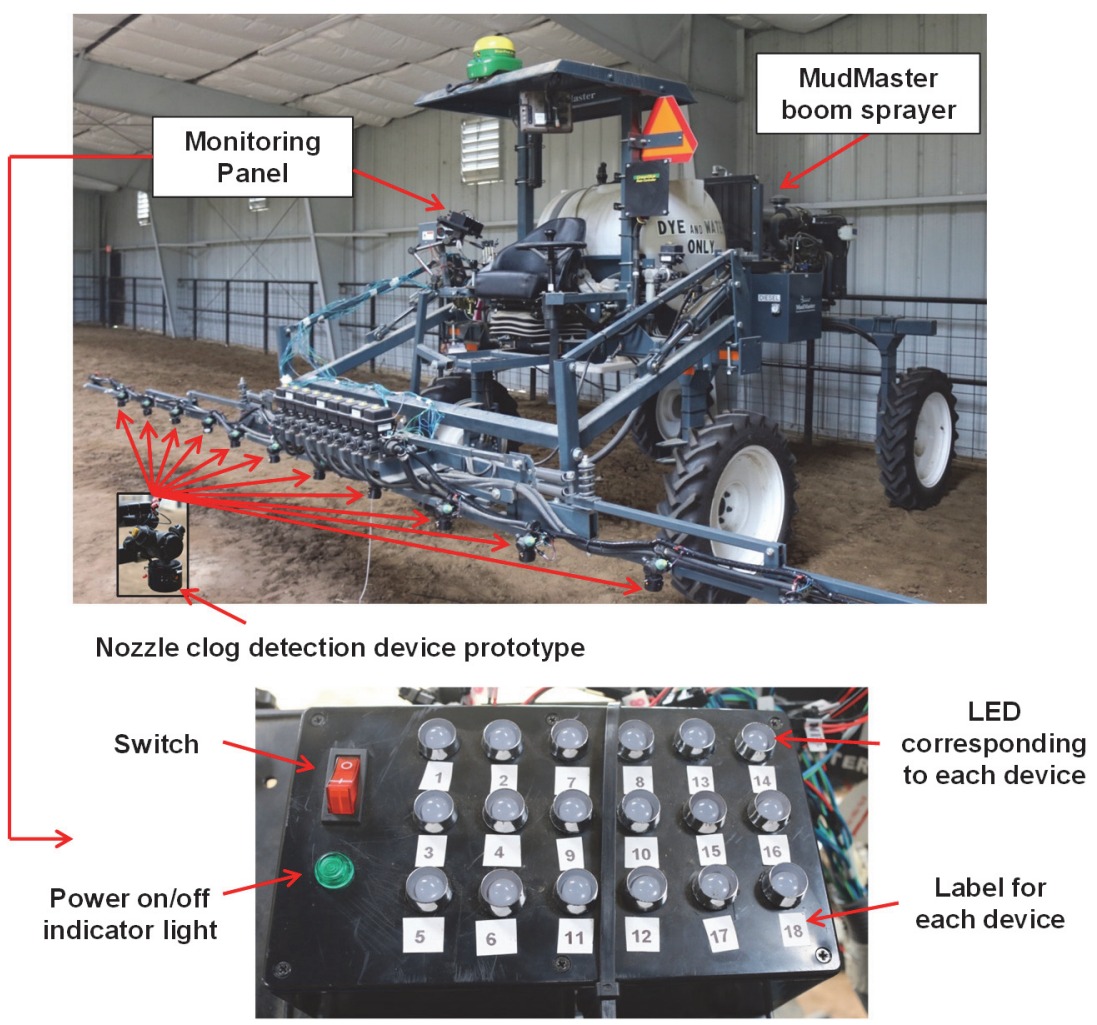

Figure 6. Prototype of multiple-device system and monitoring panel installed on MudMaster boom sprayer.

flow output differs by more than $10 \%$ above or below the average of all the nozzles used. Hence, all the nozzles used in this study were considered consistent in producing similar flow outputs throughout all the tests and were not replaced.

The droplet size test was first performed using TeeJet XR8004 nozzles with both designs of the clog detection device (i.e., single pair and multiple pairs of prongs). Thus, comparisons were made between three treatments: withoutdevice, with-device (single pair of prongs), and with-device (multiple pairs of prongs). However, after observing a decreased probability of false positives with multiple pairs of prongs (i.e., false indication of clogging due to possible disorientation of the device), all subsequent tests (i.e., droplet size test for John Deere PSULDQ2004, and spray pattern and spray coverage tests for both nozzle types) were conducted for only two treatments: without-device and with-device with multiple pairs of prongs (henceforth referred to as with-device).

During the tests with the TeeJet XR8004 nozzles, the average air temperature and relative humidity in the experiment site were $25.2^{\circ} \mathrm{C}$ and $75.7 \%$. During the tests with the John Deere PSULDQ2004 nozzles, the average temperature and relative humidity were $30.8^{\circ} \mathrm{C}$ and $68.9 \%$. Because the tests were conducted indoors, and the wind speed was zero throughout the tests, the environmental conditions were not considered significant to influence the droplet size test.

As shown in figure 7, the cumulative percentage volume of the droplet size spectrum for both nozzle types at each pressure followed similar trends among treatments by visual observation. To indicate similarity based on statistical analysis, the average VMD was used to compare treatments. The average VMDs between treatments at different pressures for the two types of nozzles are shown in figure 8 . The spray droplets for all treatments at different pressures for the two nozzle types were classified as "fine" because their average VMDs were within the range of 145 to $225 \mu \mathrm{m}$ (Hipkins and Grisso, 2014). However, the interaction between treatment and pressure was not significant for VMD when tested with both the TeeJet XR8004 ( $\mathrm{p}=0.4565)$ and John Deere PSULDQ2004 $(\mathrm{p}=0.7944)$ at $5 \%$ significance level. Theoretically, VMD decreases with increasing pressure (Hills and Gu, 1989), but an inconsistent trend was found in our study (fig. 8). The average VMD decreased when pressure increased from 207 to $276 \mathrm{kPa}$ but increased when pressure increased from 276 to $345 \mathrm{kPa}$. This inconsistency, which was observed for both nozzle types, could be an intrinsic characteristic of the sprayer system or instrumentation used for the tests, or an interaction between the two. This finding needed further investigation.

The main effect of treatment on average VMD was further investigated because the interaction between treatment and pressure was not significant. The average VMDs for the TeeJet XR8004 nozzle (fig. 9a) were 195, 199, and $177 \mu \mathrm{m}$, respectively, for the without-device, with-device (single pair of prongs), and with-device (multiple pairs of prongs) treatments, which were not significantly different from each other. Hence, use of the nozzle clog detection device on this extended-range flat tip nozzle did not significantly influence the droplet size characteristics of the spray. For the John Deere PSULDQ2004 nozzle (fig. 9b), the average VMD of the without-device treatment was $178 \mu \mathrm{m}$, which was significantly higher than that of the with-device treatment with multiple pairs of prongs $(157 \mu \mathrm{m})$. The resulting sprays for both treatments are classified as "fine" based on droplet size, 

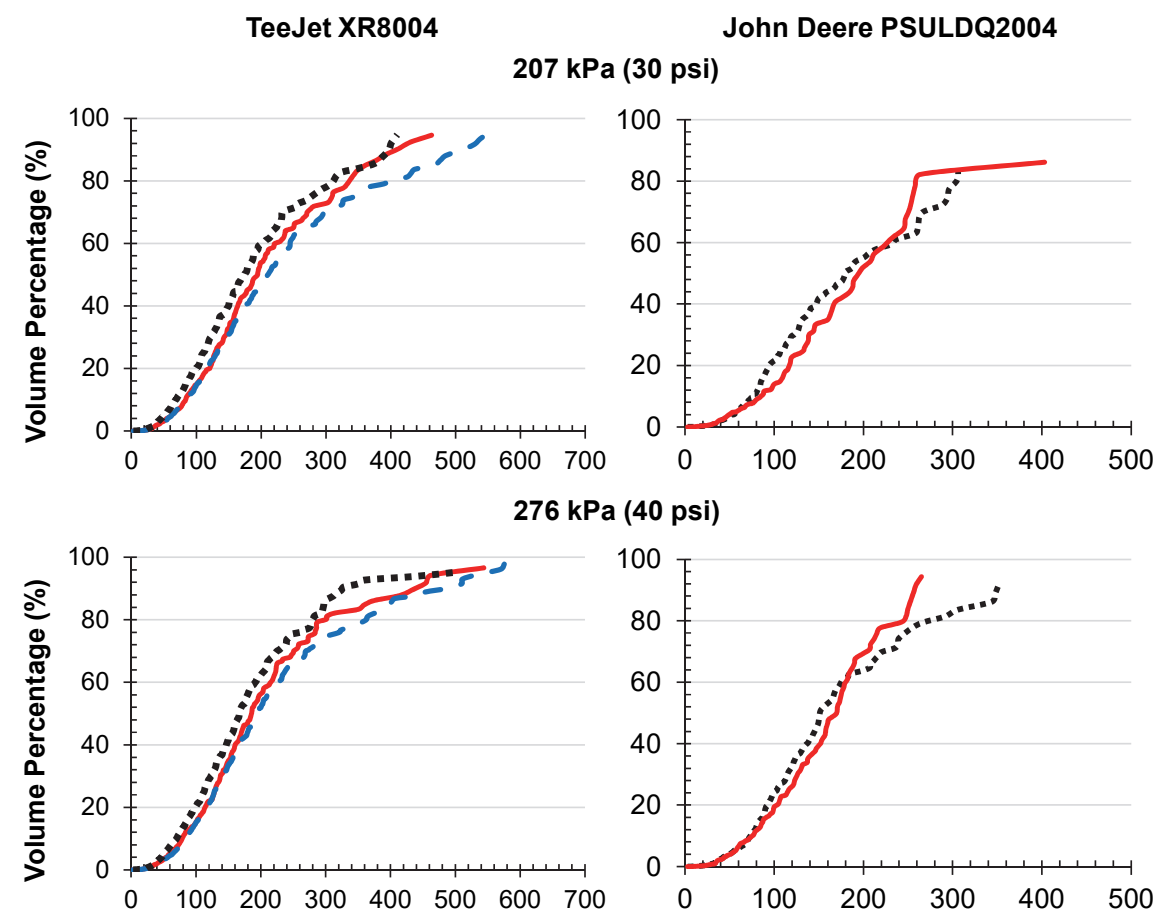

$345 \mathrm{kPa}(50 \mathrm{psi})$
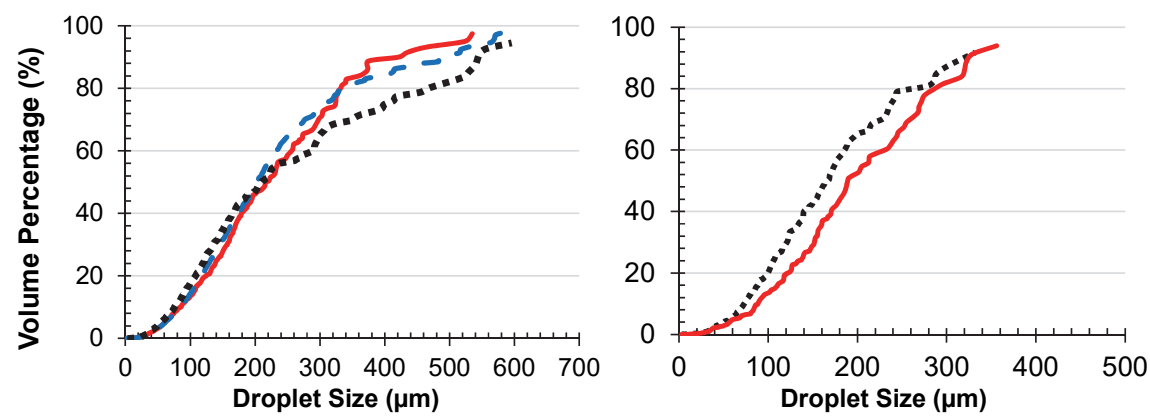

Without-Device

- With-Device (single pair of prongs)

....... With-Device (multiple pairs of prongs)

Figure 7. Cumulative volume percentage over droplet size spectrum for different treatments with two nozzles types at different pressures.

(a) TeeJetXR8004

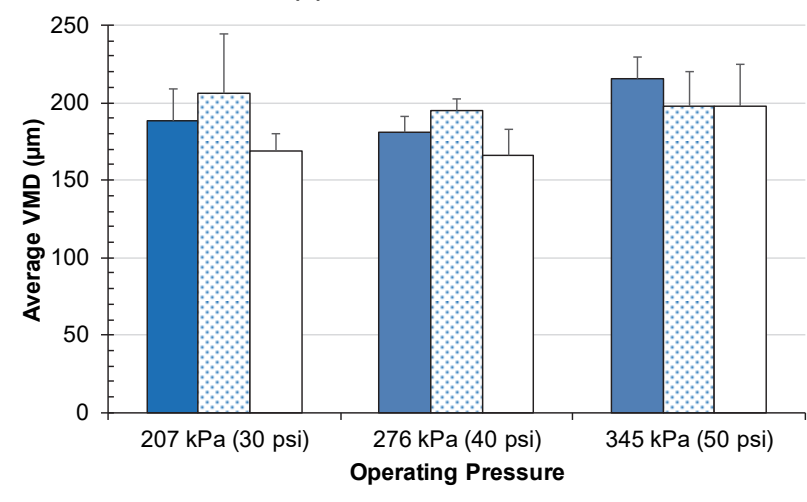

$\square$ Without-Device

- With-Device (single pair of prongs)

$\square$ With-Device (multiple pairs of prongs) (b) John Deere PSULDQ2004

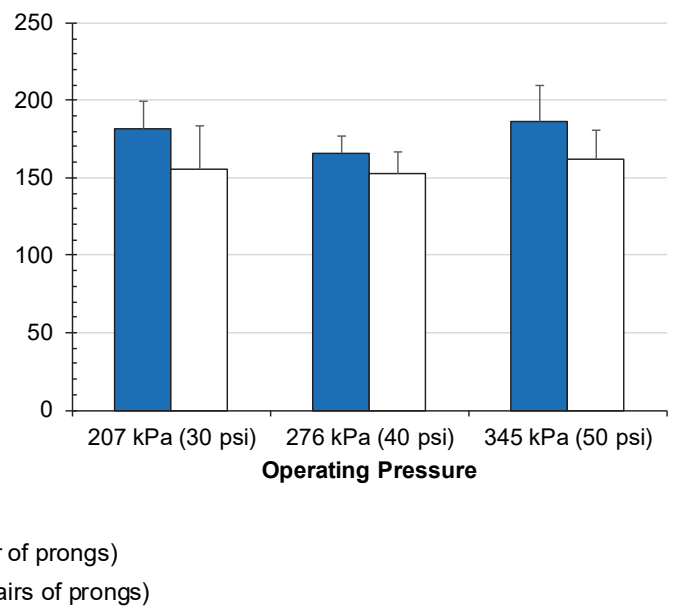

Figure 8. Mean volume median diameter (VMD) for (a) XR8004 and (b) PSULDQ2004 nozzles for each treatment and pressure. 
(a) TeeJet Xr8004

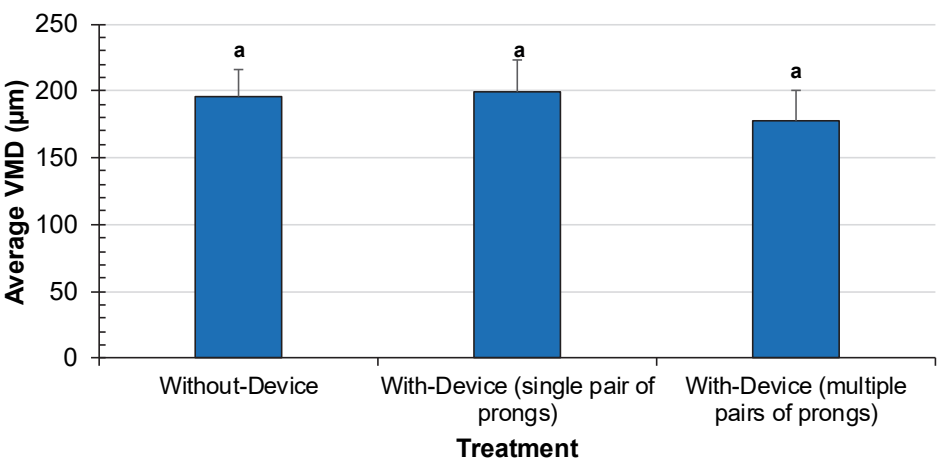

(b) John Deere PSULDQ2004

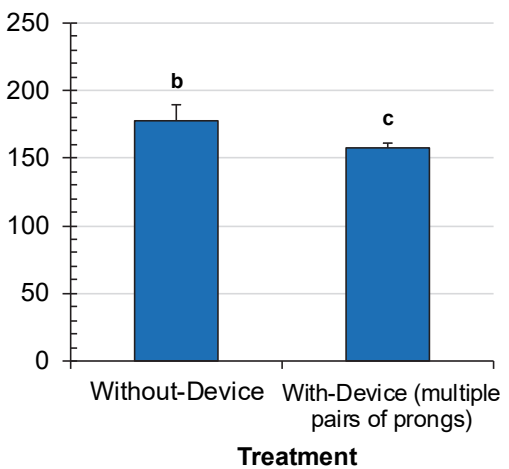

Figure 9. Mean volume median diameter (VMD) for (a) TeeJet XR8004 and (b) John Deere PSULDQ2004 nozzles for each treatment. Bars with the same letter are not significantly different at 0.05 significance level using Tukey's HSD test.

and the reduction in droplet size (average VMD) when using the device could be due to the larger droplets being split into smaller sizes by the prongs of the device during spraying.

Notably, the ultra low-drift nozzle type is designed to reduce spray drift potential by producing larger air-filled droplets (Deere, 2017). Accordingly, the John Deere PSULDQ2004 nozzle should have produced "ultra coarse" $(>650 \mu \mathrm{m})$ droplets at 207 and $276 \mathrm{kPa}$ and "extremely coarse" (501 to $650 \mu \mathrm{m})$ droplets at $345 \mathrm{kPa}$ without the nozzle clog detection device (Deere, 2017; Hipkins and Grisso, 2014). Hence, it was intriguing to observe "fine" (<200 $\mu \mathrm{m})$ droplets at these pressures. Nonetheless, considering that the larger droplets produced were air-filled and that the hot-wire method of the DC-IV droplet counter depends on the cooling effect of the liquid component of the droplets, it can be established that the hot-wire probe was not effective in capturing the actual size of the air-filled ultra low-drift droplets. Commonly, laser-based instruments have been used effectively for contactless analysis of spray droplets (Nuyttens et al., 2006). In addition, because the measured droplet sizes from the John Deere PSULDQ2004 nozzle were smaller than those from the TeeJet XR8004 nozzle at all pressures, the effective amount of liquid contained in droplets from the former was always less than that contained in droplets from the latter. Further investigation is needed to compare droplet size measurements for the same agricultural nozzle types using the DC-IV droplet counter and the commonly used laserbased instruments to justify its performance.

For both nozzle types, the VMD of the with-device (multiple pairs of prongs) treatment decreased numerically as compared to the VMD of the without-device treatment. The reduction in droplet size is a concern for increased drift potential. Droplet sizes of less than $150 \mu \mathrm{m}$ are considered highly prone to drift (Ramsdale and Messersmith, 2001; Ferguson et al., 2016). Although the VMD of the with-device treatment for both nozzle types was not less than $150 \mu \mathrm{m}$, the decrease in droplet size when using the nozzle clog detection device will probably increase the drift potential. Further tests are needed to evaluate the extent of this challenge with a wider range of nozzle types.

The spray pattern was affected by using the nozzle clog detection device, as shown in figure 10 . The spray pattern of the without-device treatment for the TeeJet XR8004 nozzle at each pressure had an inverted bell shape, while that for the with-device treatment had a near-bell shape. The volume of spray collected in patternator channels $1,2,3,4,5,15$, and 16 (i.e., at the overlapping ends of adjacent nozzles) were always lower with the device compared to without the device. On the other hand, there were always higher volumes of spray collected in patternator channels 8 to 13 (in the middle section of spray) with the device compared to without the device. This indicates that as spray from the nozzle passed across the prongs of the device, droplets at both ends of the spray were deviated toward the middle section, causing more volume to be collected in the middle channels of the patternator. When tested with the John Deere PSULDQ2004 nozzles, the spray pattern was not consistent for both treatments at different pressures. The spray pattern was again affected by the disturbance of the prongs, but the effect was not consistent, which may be due to inconsistent orientation of the prongs in the device attached to each nozzle tested.

Figure 11a shows the average CVs for the two treatments at different pressures for the TeeJet XR8004 nozzle. The interaction between treatment and pressure was not significant $(p$-value $=0.0693)$ at 5\% significance level. The CVs of each treatment at all pressures were averaged and compared, as shown in figure $11 \mathrm{~b}$. The mean CV when using the device was $6.21 \%$, which was not significantly different from when the device was not used (5.57\%). Furthermore, the mean CV using the device was less than $7 \%$, suggesting that the spray distribution was extremely uniform under controlled conditions (Spraying Systems, 2014). The results indicate that the spray pattern was not significantly affected by using the device, and uniform spray distribution was obtained with the extended-range flat tip nozzle.

When tested with the John Deere PSULDQ2004 nozzle, the interaction between treatment and pressure was significant $(\mathrm{p}<0.001)$ at $5 \%$ significance level (fig. 12). The mean $\mathrm{CV}$ with the device was higher than the mean $\mathrm{CV}$ without the device at each pressure. The mean CV difference between the without-device and with-device treatments was highest $(7.8 \%)$ at the lowest pressure $(207 \mathrm{kPa})$. Smaller mean $\mathrm{CV}$ differences between treatments were observed at $276 \mathrm{kPa}(1 \%)$ and $345 \mathrm{kPa}(2 \%)$. Generally, decreasing pressure forms larger droplets. The larger droplets at the lowest pressure $(207 \mathrm{kPa})$ may have been separated into finer droplets when they came into contact with the prongs of the 
device. The finer droplets may not have deposited in the same patternator channels as the coarser droplets produced when the device was not used. Therefore, the inconsistent collection of the finer droplets in different patternator channels caused a non-uniform spray distribution. Among the pressures tested, only the with-device treatment at the

TeeJet XR8004

John Deere PSULDQ2004

$207 \mathrm{kPa}$ (30 psi)
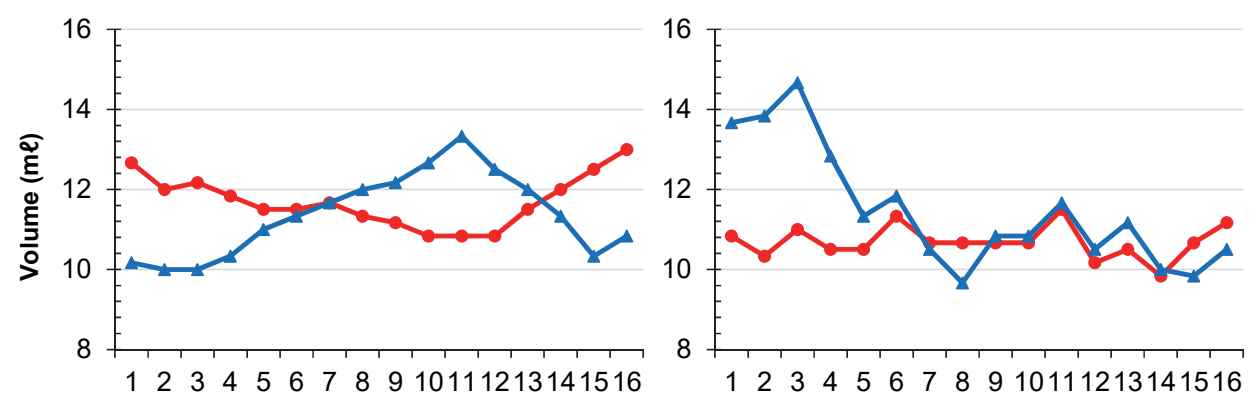

$276 \mathrm{kPa}(40 \mathrm{psi})$
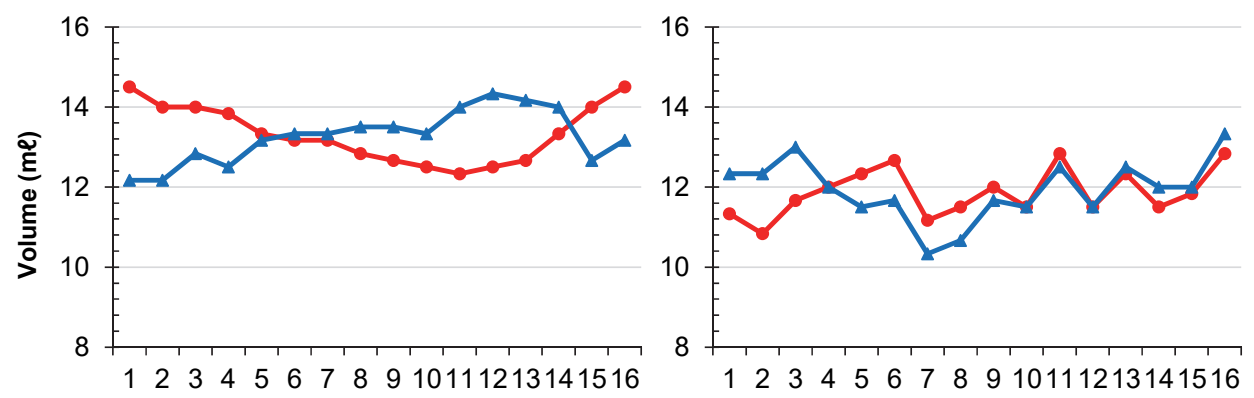

$345 \mathrm{kPa}(50 \mathrm{psi})$
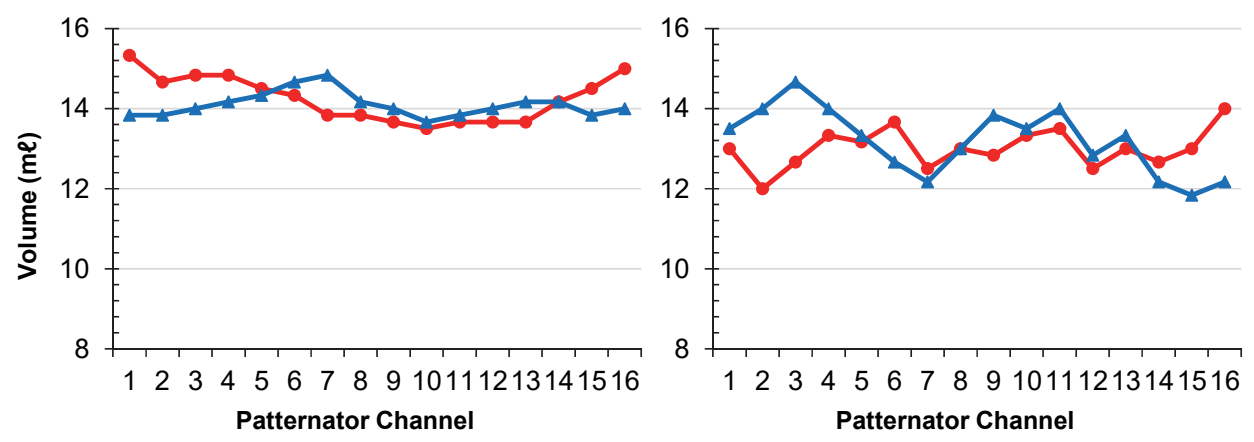

$\rightarrow$ Without-Device

$\simeq$ With-Device

Figure 10. Volume collected in each patternator channel for each treatment with two nozzles types at different pressures.

(a)

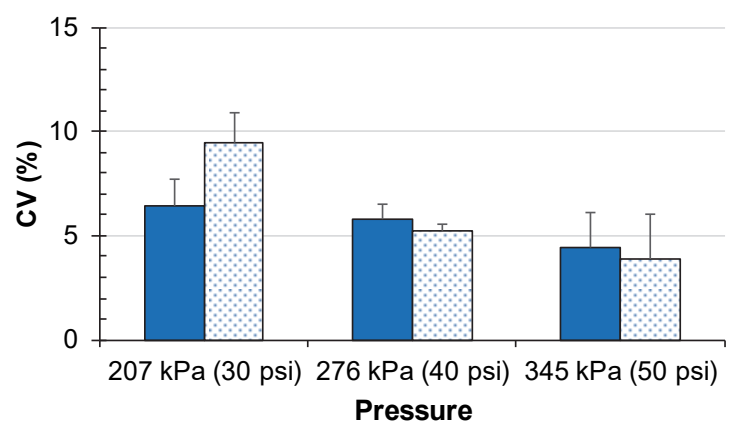

$\square$ Without-Device $\square$ With-Device (b)

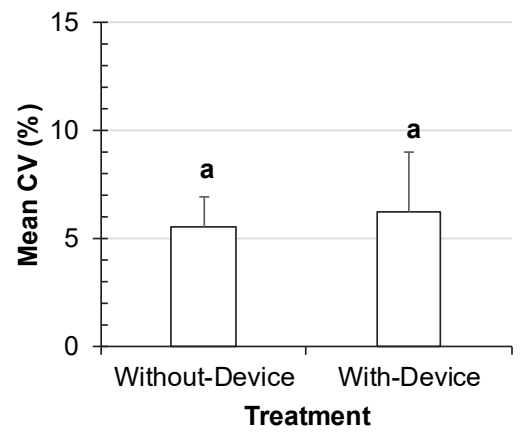

Figure 11. (a) Coefficient of variation (CV) for each treatment at different pressures and (b) mean CV for each treatment with TeeJet XR8004 nozzle. Bars with the same letter are not significantly different at 0.05 significance level using Tukey test. 


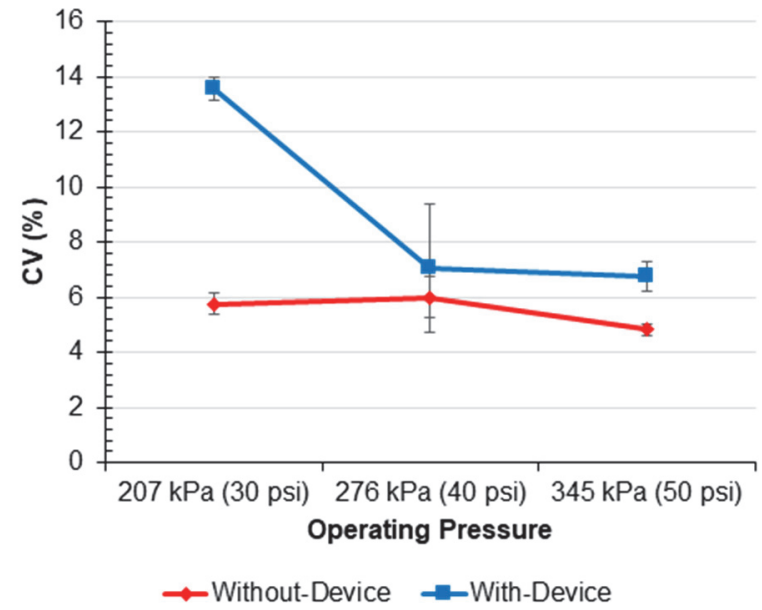

Figure 12. Coefficient of variation (CV) for each treatment at different pressures for John Deere PSULDQ2004 nozzle with significant interaction between treatments and pressures.

highest pressure $(345 \mathrm{kPa})$ had a mean $\mathrm{CV}$ of less than $7 \%$. This implies that the spray distribution was uniform when using the device with the ultra low-drift nozzle at high pressure, such as $345 \mathrm{kPa}$.

\section{SPRAY COVERAge TeSt in Field Conditions}

The three sprayer travel speeds obtained from the speed calibration test are listed in table 1 . To obtain excellent spray distribution, a working pressure range of 103 to $414 \mathrm{kPa}(15$ to $60 \mathrm{psi}$ ) should be used for TeeJet XR8004 nozzles (Spraying System Co., 2014). The recommended speed range is 3.6 to $4.5 \mathrm{~m} \mathrm{~s}^{-1}$ (8 to $10 \mathrm{mph}$ ) for an application rate of $94 \mathrm{~L} \mathrm{ha}^{-1}$ (10 gpa) and 2.2 to $3.1 \mathrm{~m} \mathrm{~s}^{-1}$ (5 to $7 \mathrm{mph}$ ) for an application rate of $187 \mathrm{~L} \mathrm{ha}^{-1}$ (20 gpa). Thus, the suitable speeds needed to attain the 94 and $187 \mathrm{~L} \mathrm{ha}^{-1}$ application rates were S3 and S2, respectively. For John Deere PSULDQ2004 nozzles, the working pressure range is 137 to $793 \mathrm{kPa}$ (20 to $115 \mathrm{psi}$ ) (Deere, 2017). To attain the $94 \mathrm{~L} \mathrm{ha}^{-1}$ application rate, the recommended speed is at least $5 \mathrm{~m} \mathrm{~s}^{-1}(11.2 \mathrm{mph})$. The highest speed (S3) was used for the $94 \mathrm{~L} \mathrm{ha}^{-1}$ application rate. However, the working pressure may be reduced to less than 137 $\mathrm{kPa}$ for the rate controller to attain the $94 \mathrm{~L} \mathrm{ha}^{-1}$ application rate. S2 was used for the $187 \mathrm{~L} \mathrm{ha}^{-1}$ application rate because the recommended speed is at least $2.5 \mathrm{~m} \mathrm{~s}^{-1}(5.6 \mathrm{mph})$.

None of the environmental parameters met the $p<0.05$ criterion for predicting the average percentage spray coverage, as shown in tables 2 and 3 for both nozzle types. Thus, the influence of environmental conditions on the spray coverage in this study was confirmed to be not significant.

The sprayed water-sensitive strips collected from both treatments (with-device and without-device) at both application rates (94 and $187 \mathrm{~L} \mathrm{ha}^{-1}$ ) for the two nozzle types appeared to be similar by visual inspection (figs. 13 to 16). The calculated percentage spray coverage for the with-device treatment was $20 \%$, which was significantly higher than that of the without-device treatment (14.4\%) at the 94

Table 1. Three travel speeds obtained from speed test.

\begin{tabular}{ccc}
\hline Speed ID & Speed $\left(\mathrm{m} \mathrm{s}^{-1}\right)$ & Speed $(\mathrm{mph})$ \\
\hline S1 & 1.8 & 4.1 \\
S2 & 2.8 & 6.2 \\
S3 & 4.2 & 9.4 \\
\hline
\end{tabular}

Table 2. Multiple linear regression results for determining the effect of environmental parameters on average percentage spray coverage with TeeJet XR8004 nozzle.

\begin{tabular}{ccccc}
\hline Parameters & Coeff. & Std. Error & t-Value & p-Value \\
\hline Constant & 366.951 & 279.766 & 1.312 & 0.226 \\
Mean air temp. $\left({ }^{\circ} \mathrm{C}\right)$ & -12.177 & 11.001 & -1.107 & 0.301 \\
Mean wind speed $\left(\mathrm{m} \mathrm{s}^{-1}\right)$ & -1.324 & 3.512 & -0.377 & 0.716 \\
Mean RH $(\%)$ & -1.879 & 1.179 & -1.594 & 0.150 \\
\hline
\end{tabular}

Table 3. Multiple linear regression results for determining the effect of environmental parameters on average percentage spray coverage with John Deere PSULDQ2004 nozzle.

\begin{tabular}{ccccc}
\hline Parameters & Coeff. & Std. Error & t-Value & p-Value \\
\hline Constant & -247.517 & 146.826 & -1.686 & 0.130 \\
Mean air temp. $\left({ }^{\circ} \mathrm{C}\right)$ & 11.827 & 6.065 & 1.950 & 0.087 \\
Mean wind speed $\left(\mathrm{m} \mathrm{s}^{-1}\right)$ & -2.504 & 1.533 & -1.634 & 0.141 \\
Mean RH $(\%)$ & 0.131 & 0.806 & 0.163 & 0.875 \\
\hline
\end{tabular}

$\mathrm{L} \mathrm{ha}^{-1}$ application rate when tested with the XR8004 nozzle (fig. 17). In general, spray coverage increases with decreasing droplet size (Wolf, 1997). The droplet size decreased when the nozzle clog detection device was used, as discussed earlier; hence, the spray coverage increased. At the $187 \mathrm{~L} \mathrm{ha}^{-1}$ application rate, the percentage spray coverage was not significantly different among treatments. The results imply that using the device with extended-range flat tip nozzles will not significantly influence the spray coverage at $187 \mathrm{~L} \mathrm{ha}^{-1}$ but will increase the spray coverage at 94 $\mathrm{L} \mathrm{ha}^{-1}$.

Based on the foregoing results, the droplet size decreased when the prototype device was used. A decrease in droplet size should generally increase the spray coverage. However, the opposite result was shown for the John Deere PSULDQ2004 nozzle. The percentage spray coverage for the with-device treatment was significantly lower than that of the without-device treatment, with a difference of $6 \%$ at the $94 \mathrm{~L}$ $\mathrm{ha}^{-1}$ application rate (fig. 18a). When using this nozzle type, the pressure might be lowered to less than $138 \mathrm{kPa}$, which is below the working pressure range, due to the limitation of the highest speed attained by the MudMaster boom sprayer. This may result in uncertainty in the nozzle performance, subsequently causing this anomaly. At the $187 \mathrm{~L} \mathrm{ha}^{-1}$ application rate, there was no significant difference in percentage spray coverage between treatments, as shown in figure 18b. This result indicates that when using the nozzle clog detection device, the spray coverage may not be significantly affected at the 187 $\mathrm{L} \mathrm{ha}^{-1}$ application rate.

\section{Conclusions}

Prototypes of an agricultural nozzle clog detection system with 18 devices to be attached to 18 nozzles along the boom of a precision boom sprayer were successfully developed and tested in this study. All the devices worked well in detecting clogging in nozzles. When the spray from a given nozzle makes contact with the prongs of a given device attached to the nozzle, an LED on the device and a corresponding LED on a monitoring panel light up. When the nozzle stops spraying, both LEDs go off.

In testing the device with TeeJet XR8004 nozzles, the spray quality characteristics (droplet size, spray pattern, and spray coverage) were not significantly affected. For droplet 


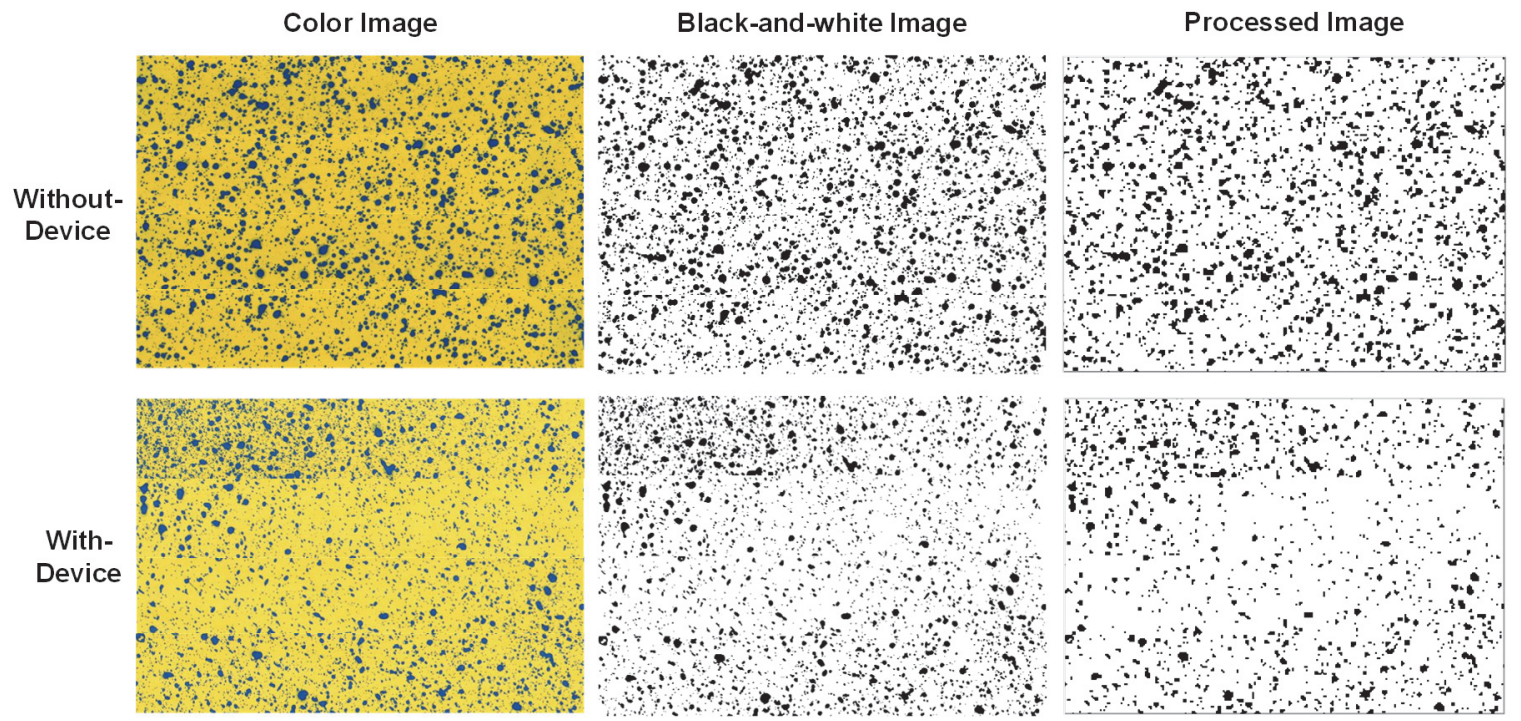

Figure 13. Scanned water-sensitive strips for different treatments at $94 \mathrm{~L} \mathrm{ha}^{-1}$ application rate with TeeJet XR8004 nozzle.
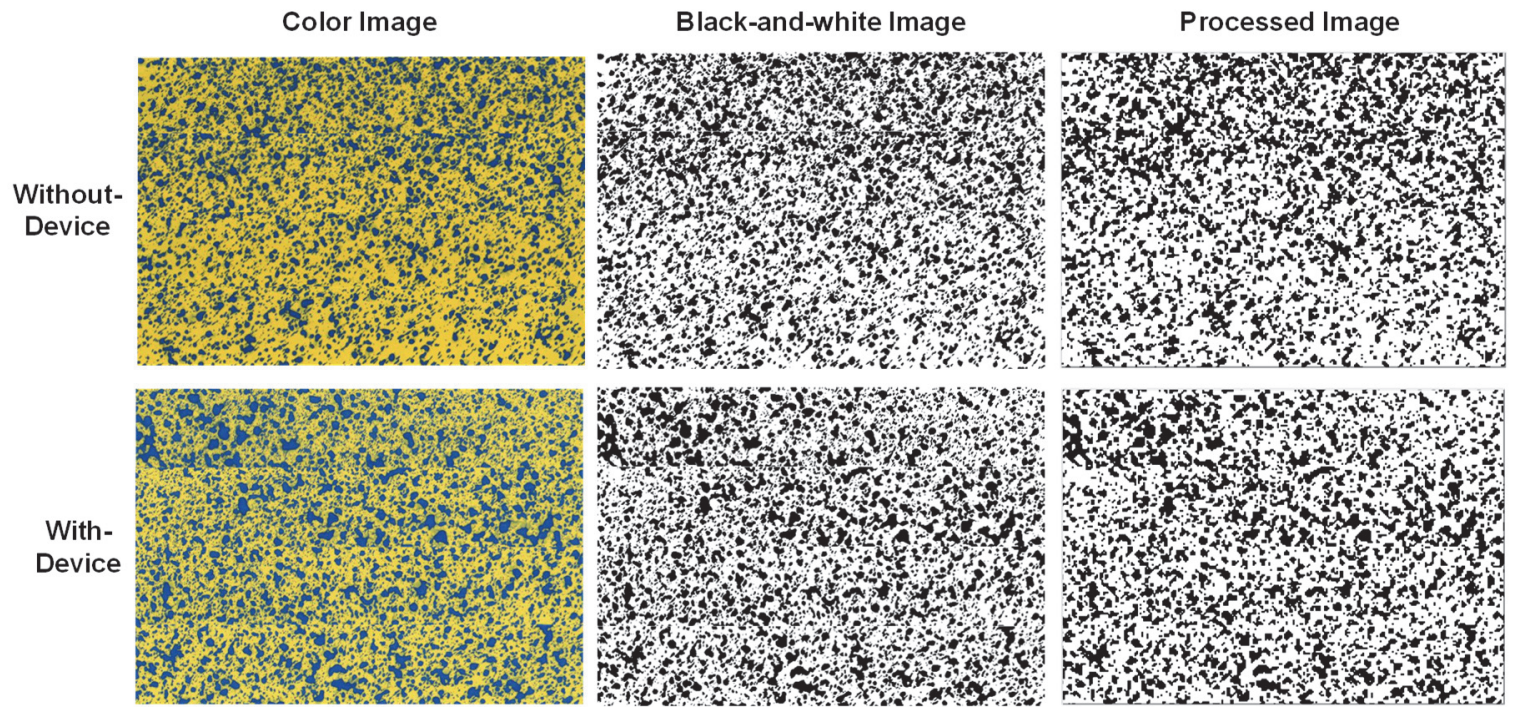

Figure 14. Scanned water-sensitive strips for different treatments at $187 \mathrm{~L} \mathrm{ha}^{-1}$ application rate with TeeJet XR8004 nozzle.
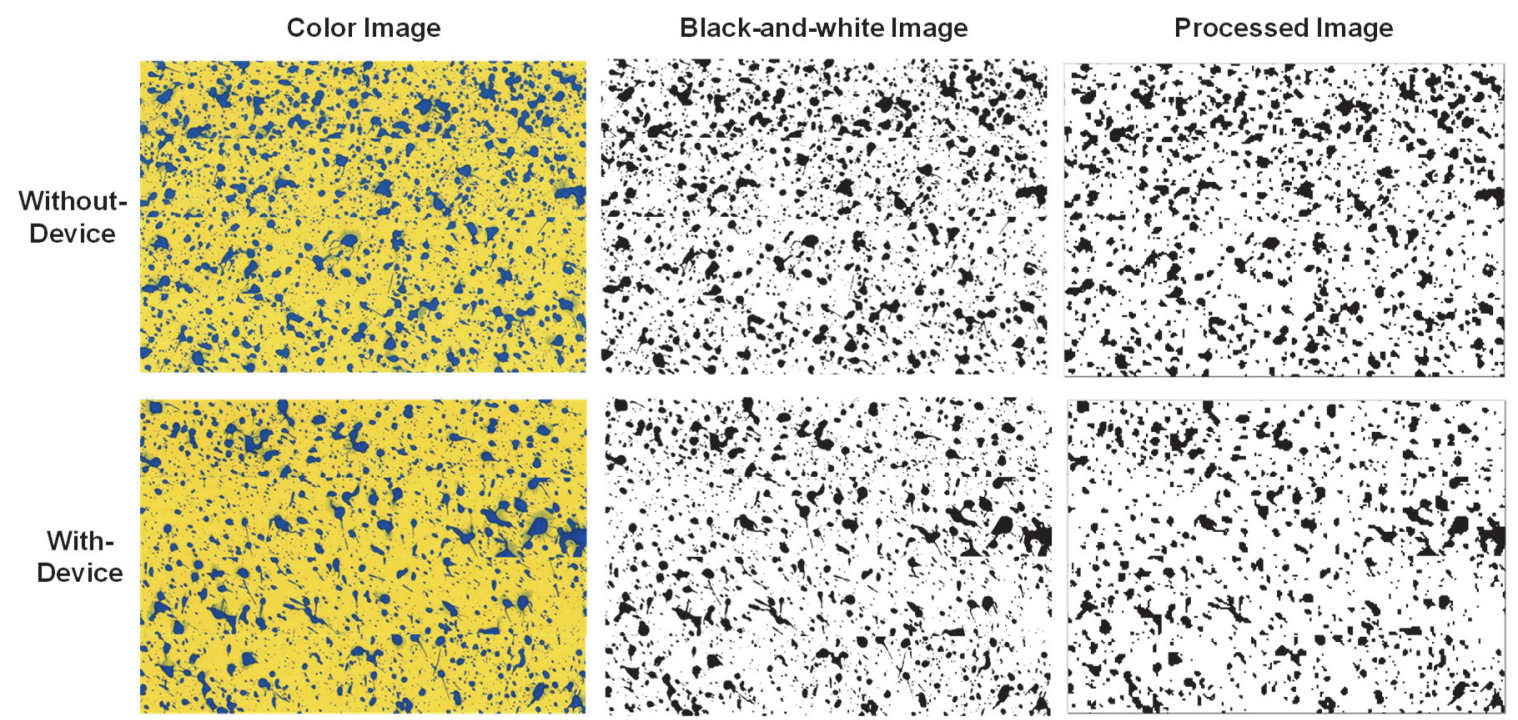

Figure 15. Scanned water-sensitive strips for different treatments at $94 \mathrm{~L} \mathrm{ha}^{-1}$ application rate with John Deere PSULDQ2004 nozzle. 


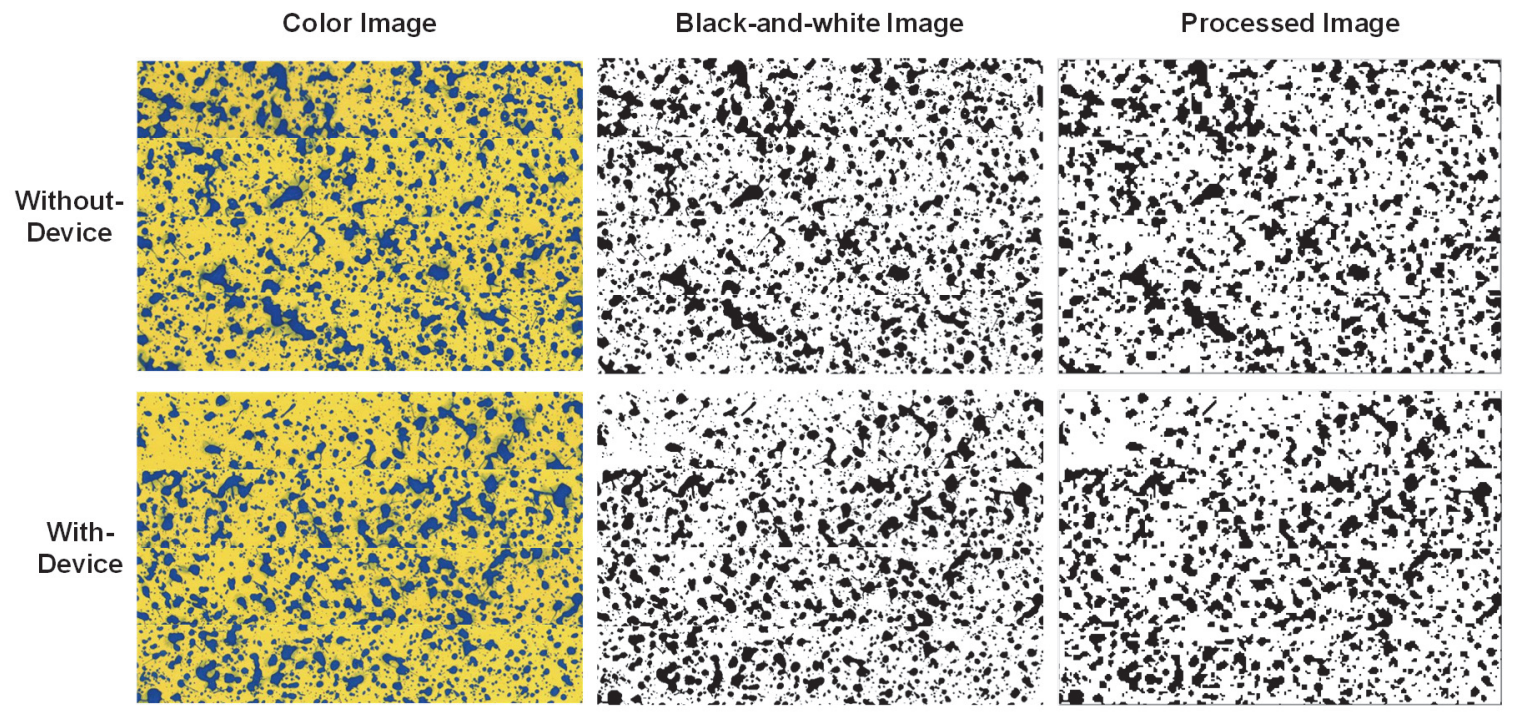

Figure 16. Scanned water-sensitive strips for different treatments at $187 \mathrm{~L} \mathrm{ha}^{-1}$ application rate with John Deere PSULDQ2004 nozzle.

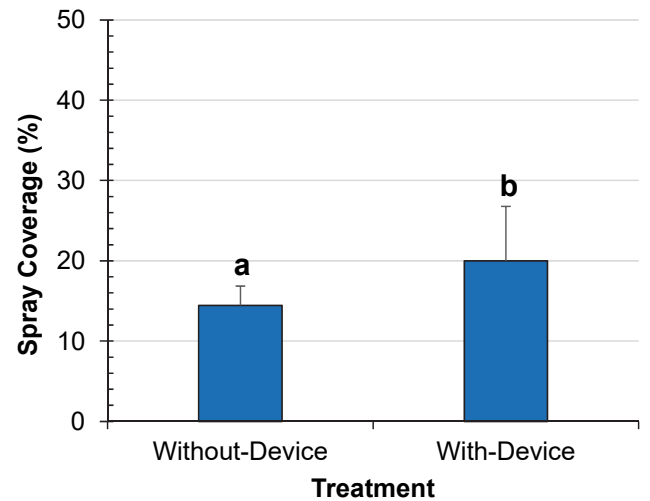

(a)

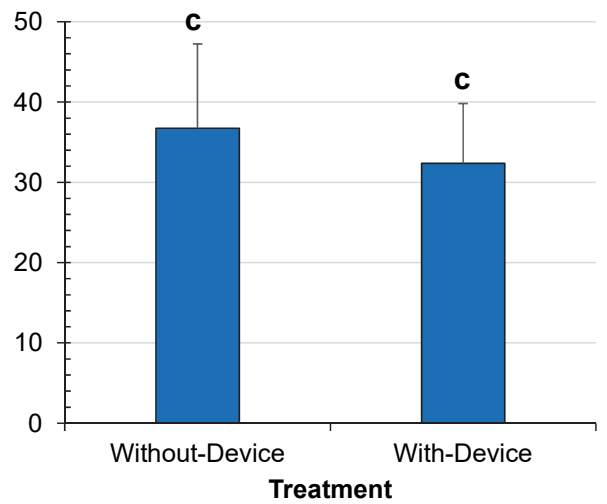

(b)

Figure 17. Mean spray coverage for different treatments at application rates of (a) $94 \mathrm{~L} \mathrm{ha}^{-1}$ and (b) $187 \mathrm{~L} \mathrm{ha}^{-1}$ for TeeJet XR8004 nozzle. Bars with the same letter are not significantly different at 0.05 significance level using Tukey test.

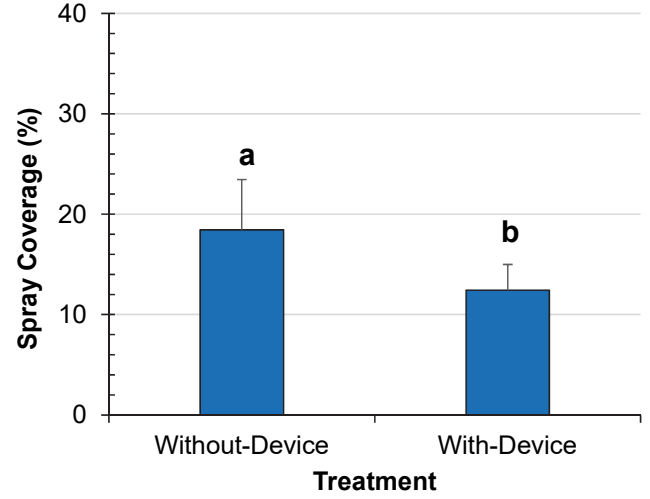

(a)

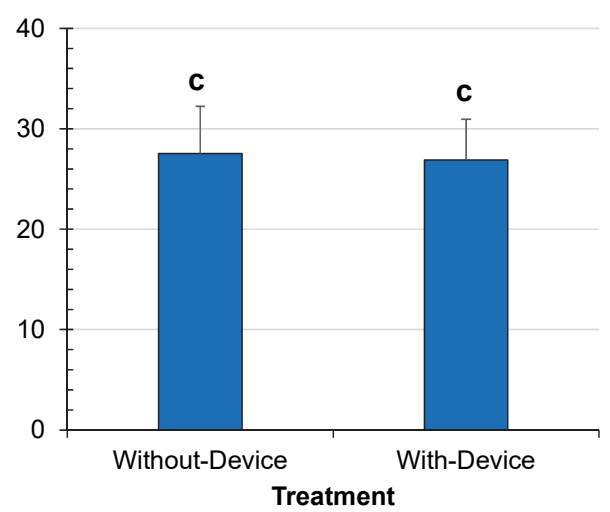

(b)

Figure 18. Mean spray coverage for different treatments at application rates of (a) $94 \mathrm{~L} \mathrm{ha}^{-1}$ and (b) $187 \mathrm{~L} \mathrm{ha}^{-1}$ for John Deere PSULDQ2004 nozzle. Bars with the same letter are not significantly different at 0.05 significance level using Tukey test.

size, the average VMD among three treatments (without-device, with-device with a single pair of prongs, and with-device with multiple pairs of prongs) were not significantly different from each other. Moreover, for spray pattern, although there were some differences in the volume of spray collected in some patternator channels, the CVs were not significantly different between the without-device and with-device treatments. The mean $\mathrm{CV}$ for when using the device was less than $7 \%$, indicating that the spray distribution was uniform. The spray coverage at the $94 \mathrm{~L} \mathrm{ha}^{-1}$ application rate was significantly higher when using the device than when the device was not used. There was no significant difference in spray 
coverage at the $187 \mathrm{~L} \mathrm{ha}^{-1}$ application rate when the device was not used.

In contrast, most of the spray quality characteristics were affected when using the device with John Deere PSULDQ2004 nozzles. In the droplet size test, the average VMD of the with-device treatment was significantly lower than that of the without-device treatment. For the spray pattern test, there were some differences in the volume of spray collected in some of the patternator channels. Only the mean CV of the with-device treatment at $345 \mathrm{kPa}$ was less than $7 \%$, indicating uniform spray distribution. The spray coverage was significantly lower when using the nozzle clog detection device than when not using the device at the $94 \mathrm{~L} \mathrm{ha}^{-1}$ application rate, which may be due to uncertainty in the performance of the nozzles. At the $187 \mathrm{~L} \mathrm{ha}^{-1}$ application rate, the spray coverage was not significantly different between the without-device and with-device treatments.

Based on the results of these tests, this new nozzle clog detection system has potential for detecting clogging in nozzles without significantly affecting the spray quality characteristics (i.e., droplet size, spray pattern, and spray coverage) for the extended-range nozzle type (TeeJet XR8004) but not for the ultra low-drift nozzle type (John Deere PSULDQ2004). To increase the reliability and performance of this new technology, further improvements of the prong design need to be considered. Future spray quality tests should be conducted with different types of nozzles of different sizes to cover the wide range of nozzles used by producers.

\section{ACKNOWLEDGEMENTS}

This study was supported by USDA-NIFA Hatch Project No. 1005836. Funding and facility support were also provided by the College of Agriculture, Engineering, and Technology at Arkansas State University and the Division of Agriculture at the University of Arkansas. The authors also acknowledge the assistance of the following student members of the Precision Application Technology Lab for their assistance during the study: Pruthvi Raj Pola, Cyrus Dean Marbaniang, Kumar Bade, Shailaja Vemula, and Andrea Noelly Kouame. Additional thanks to Mr. Mike Johnson, AState farm manager, for coordinating the farm resources used.

\section{REFERENCES}

Anderson, J. W. (1982). Nozzle condition monitor. U.S. Patent No. $4,313,111$.

Anderson, J. W., \& Hughes, G. (1978). Spray sensing system. U.S. Patent No. 4,084,748.
Deere. (2017). Sprayer parts guide. Moline, IL: John Deere Spraying Solutions.

Ellingson, J., Tollefsrud, A., \& Bastin, B. (2014). Method and apparatus for detecting a plugged nozzle of a sprayer. U.S. Patent No. 8,833,680 B2.

Ferguson, J. C., Hewitt, A. J., \& O’Donnell, C. C. (2016). Pressure, droplet size classification, and nozzle arrangement effects on coverage and droplet number density using air-inclusion dualfan nozzles for pesticide applications. Crop Prot., 89, 231-238. https://doi.org/10.1016/j.cropro.2016.07.032

Giles, D. K. (2007). Flow control and operation monitoring system for individual spray nozzles. U.S. Patent No. 7,311,004 B2.

Grisso, R., Hipkins, P., Askew, S. D., Hipkins, L., \& McCall, D. (2013). Nozzles: Selection and sizing. Blacksburg, VA: Virginia Cooperative Extension. Retrieved from https://www.pubs.ext.vt.edu/442/442-032/442-032.html

Hills, D. J., \& Gu, Y. (1989). Sprinkler volume mean droplet diameter as a function of pressure. Trans. ASAE, 32(2), 471-476. https://doi.org/10.13031/2013.31028

Hipkins, P., \& Grisso, R. B. (2014). Droplet chart/selection guide. Blacksburg, VA: Virginia Cooperative Extension. Retrieved from https://www.pubs.ext.vt.edu/442/442-031/442-031.html

Hofman, V., \& Solseng, E. (2014). Spray equipment and calibration. Fargo, ND: North Dakota State University Extension Service.

Johnson, M. P., \& Swetnam, L. D. (1994). Sprayer nozzles: Selection and calibration. Lexington, KY: University of Kentucky Cooperative Extension Service.

Larbi, P. A. (2016). RGB2X: An RGB image data extract-export tool for digital image processing and analysis in Microsoft Excel. ASABE Paper No. 162460787. St. Joseph, MI: ASABE.

Larbi, P. A. (2018). Advancing Microsoft Excel's potential for teaching digital image processing and analysis. Appl. Eng. Agric., 34(2), 263-276. https://doi.org/10.13031/aea.12221

Larbi, P. A., \& Vong, C. N. (2019). Method and device to detect clogged nozzles. U.S. Patent No. 10,279,366.

Nuyttens, D., De Schampheleire, M., Steurbaut, W., Baetens, K., Verboven, P., Nicolai, B., ... Sonck, B. (2006). Characterization of agricultural sprays using laser techniques. Aspects Appl. Biol., 77(1), 179-188.

Petroff, R., \& Johnson, G. (2011). Maintenance, cleaning, and storage of ground sprayers. Bozeman, MT: Montana State University Extension.

Ramsdale, B. K., \& Messersmith, C. G. (2001). Drift-reducing nozzle effects on herbicide performance. Weed Tech., 15(3), 453-460. https://doi.org/10.1614/0890037X(2001)015[0453:DRNEOH]2.0.CO;2

Rogers, R. B., \& Baker, J. A. (1990). Field sprayer nozzle pattern monitor. U.S. Patent No. 4,905,897.

Spraying Systems. (2014). Catalog 51A. Wheaton, IL: TeeJet Technologies.

Vehe, D., \& van den Berg, P. (1980). Spray monitoring device and implement. U.S. Patent No. 4,193,356.

Wolf, R. (1997). Strategies to reduce spray drift. Champaign, IL: University of Illinois at Urbana-Champaign. 